\title{
A Critical Realist Reflection on the Use of Social Media as Third Space for Rights Education in Early Childhood
}

\begin{abstract}
The promotion and advancement of Rights Education in Early Childhood ought to be supported through the development of spaces that allow for interdisciplinary discourses among different stakeholders. The project \#ChildRightsChat emerged from interactions between the authors to use a digital space to promote the advancement of an interdisciplinary and global discussion about children's rights. A primary aim was to facilitate adult learning about the protection and promotion of children's rights in practice. Chats in Twitter, through structured and moderated interactions, were designed to share knowledge and experiences around specific topics. The present paper presents the authors' reflections, as moderators of \#ChildRightsChat, through a critical realist analysis. The findings explore how social media can be understood as a learning environment in 'third space', with respect to the nature of interactions that occurred, the context as a learning space, and the voices heard in the chat. The implications of social media to include global perspectives for the advancement of rights-based practice in early childhood education and care are considered.
\end{abstract}

Key words: Children's rights, critical realism; social media; reflective practice

\section{Résumé}

La promotion et l'avancement de l'éducation aux droits en petite enfance devraient être soutenus par l'élaboration d'espaces permettant des discours interdisciplinaires entre différentes parties prenantes. Le projet \#ChildRightsChat est né des interactions entre les auteurs pour l'utilisation d'un espace numérique pour promouvoir l'avancement du débat interdisciplinaire mondial sur les droits de l'enfant. L'un des principaux objectifs était de faciliter l'apprentissage des adultes sur la protection et la promotion des droits de l'enfant dans la pratique. Des discussions sur Twitter, par le biais d'interactions structurées et modérées, ont été conçues pour partager des connaissances et des expériences sur des sujets spécifiques. Le présent article présente, à travers une analyse critique réaliste, les réflexions des auteurs en tant que modérateurs du \#ChildRightsChat. Les résultats explorent la manière dont les médias sociaux peuvent être perçus comme un environnement d'apprentissage du « troisième espace », relativement à la nature des interactions qui se sont produites, $\mathrm{du}$ 
contexte comme espace d'apprentissage et des opinions entendues sur le chat. Les implications des médias sociaux pour inclure des perspectives mondiales destinées à l'avancement d'une pratique basée sur les droits en éducation et protection de la petite enfance sont prises en compte.

\section{Resumen}

La promoción y el avance de la educación de derechos en la primera infancia se deben apoyar mediante el desarrollo de espacios que den acceso a discursos interdisciplinarios entre diferentes participantes. El proyecto \#ChildRightsChat surgió de interacciones entre las autoras para utilizar un espacio digital para promover el avance de una discusión interdisciplinaria y global acerca de los derechos de los niños. Un primer objetivo era facilitar el aprendizaje de adultos sobre la protección y promoción de los derechos de los niños en la práctica. Se diseñaron conversaciones en Twitter mediante interacciones estructuradas y moderadas para compartir conocimiento y experiencias sobre temas específicos. Esta investigación incluye las reflexiones de las autoras como moderadoras de \#ChildRightsChat, mediante el uso de un análisis realista crítico. Los resultados exploran cómo las redes sociales pueden entenderse como un ambiente de aprendizaje en un 'tercer espacio', con respecto a la naturaleza de las interacciones que ocurrieron, el contexto como espacio de aprendizaje, y las voces escuchadas en el chat. Se tuvieron en cuenta las implicaciones de redes sociales que incluyen perspectivas globales para el avance de prácticas basadas en el derecho en la educación y el cuidado preescolar.

\section{Introduction}

This paper explores the challenges and the opportunities associated with the development and establishment of a unique children's rights focused twitter chat as a third space for authentic - in Freire's (1993) sense- learning through engagement, sharing and exploration. 
Early childhood and children's rights scholars have identified the need for promotion of critically engaged dialogues in the recognition of children's rights (Osgood, 2006; Robson, 2016), by exploring and challenging the complexities in the intersections between theory, practice and policy. Social media has also been acknowledged as a viable medium for three types of knowledge exchange in academia for teaching and learning opportunities (Kivunja, 2015), networking (Kortelainen \& Katvala, 2012), and scholarly communication (Haustein et al., 2015). Twitter, as a social networking platform, provides a means for knowledge exchange, through which users can publish short messages that are visible to other users and which provides opportunities for interactions between users. Since 2018, \#ChildRightsChat on Twitter has provided a digital environment to dialogue about children's rights and the protection and promotion of children's rights in practice. This paper explores the opportunities and challenges of engaging different stakeholders, including practitioners in Early Childhood Education and Care (ECEC) to discuss children's rights using a social media platform.

Moody and Darbellay (2019) identified an apparent consensus on the necessity for interdisciplinary discourses in relation to children's rights. However, they noted the challenges in studying and theorising on children's rights and childhood studies. Advancement and critique of education about children's rights through interdisciplinary discourses is also important in order to reflect on the 'spaces' in which such exchanges and discussions to promote these processes can take place. Twitter has proven to be an important social media platform for critical and interdisciplinary exchanges. Even though there are several academic chats, and chats related to education or human rights, there were none, at the inception of this project, which had specifically addressed children's rights.

From 2018, a project with the hashtag \#ChildRightsChat emerged from interactions between the authors. It was conceptualised as a digital 'third' space with an overall aim to facilitate learning about children's rights. This paper, informed by practices of reflexivity in child-centred research (Gillett-Swan \& Sargeant, 2018), explores opportunities and limitations of using Twitter as a third space for education on children's rights. This exploration was conducted using a critical realist lens (Bashkar, 
2017). It considers three levels of reality in relation to three themes: interaction, context, and voice. These reflect elements of third space (McArthur \& White, 2016).

\section{The Rights of the Child in Early Childhood}

The thirtieth anniversary of the United Nations Convention of the Rights of the Child [UNCRC] (United Nations, 1989) stands as an opportunity to reflect and celebrate achievements and progress made in furthering awareness of children's rights, and also to assess the gaps and the opportunities for further development. Within the field of early childhood, an undeniable and crucial gain in realising the implementation of the rights of young children (under 8 years of age) was the introduction of the General Comment 7 (GC7). Released in 2005 by the United Nations Office for the High Commissioner for Human Rights [OHCHR], GC7 introduced the ECEC agenda in the discourse on children's rights. It is worth noting that, while the introduction of the GC7 is a positive outcome, the level of recognition and understanding of its existence is highly variable. As Vaghri and colleagues (2011, p. 180) argue “... while GC7 represents authoritative guidance to state parties in fulfilling their $\mathrm{CRC}$ obligations to young children, without a corresponding operationalized framework of indicators, GC7 has very limited practical value and, as a result, has remained underutilized."

Although the specific mention of young children and their rights is recognised as a crucial achievement, published literature raises concerns in relation to a number of limitations. The most contested point is that ECEC is positioned as a fundamental right, rather than as being shaped by rights. Under this circumstance, rather than focusing on the development of a rights-based discourse within ECEC, the focus in on securing universal and accessible ECEC provision as a right (Arrabal, 2015; Herczog, 2012). Aside from the critiques behind the universalisation of ECEC (Penn, 2002), a main cause for concern is the lack of focus on the nature and quality of ECEC provisions.

The framing of ECEC as a stepping stone into the future is identified as another problematic element in the rights-based discourse. Whilst there is a growing consensus on the need to shift discourses of childhood from 'becoming' to 'being' (Cook, 2015), or a combination of the two (Davies, 2014), the calls for improvement, revision and quality in ECEC provisions seem to be informed primarily by conceptualisation of early 
childhood as a social investment for the greater good (Arrabal, 2015; Jensen \& Qvortrup, 2004), moving away from a specific focus on the rights of the child. Although promoting the case for children to be recognised for their rights as citizens, there is also a critique of UNCRC for leaving an element of openness in the interpretation of 'best interest' (Penn, 2002; Rutanen \& Colus., 2014). Similarly, GC7 has left unchallenged a focus on the status of vulnerability and immaturity of young children (Vaghri et al., 2011).

Traditional ideologies of childhood and child development seem to pose an issue to the realisation of rights within the context of early childhood education. Pedagogies and practices based on beliefs of about developmentally appropriate practices (Woodhead, 2006) also limited understanding and/or application of Article 12 (participation) of the UNCRC. The pedagogies proposed by Ghirotto and Mazzoni (2013) have been connected to implementation of a rights-perspective within early childhood education (MacNaughton et al., 2007). These elements have particular importance in shaping our reflection on the possible uses and limitations of engaging scholars and practitioners in conversations on the status of children's rights in early childhood.

At a policy level, Salamon (2011) highlighted the restrictions emerging from policies grounded on pedagogies and ideologies, which are shaped by theories of development that fail to recognise the child as a social agent. This line of policy informed by developmental perspectives was identified by Woodhead (2006) as primarily related to psycho-medical roots of childhood studies. Political-economic policies, centred around theories of human capital, perceive children as investments for present gender equity and future social improvements (Woodhead, 2006) that fail to bridge requirements of both development and care and leave the child out of the picture (Campbell-Barr \& Nygård, 2014). Socio-cultural perspectives in policy-making are viewed as problematic, as conflicting with Western notions of rights and agency (Burman, 1996; Moss, 2004). An effective human rights-based policy would, in fact, not only provide a push towards a more participatory, rights-informed practice, but it could also grant a different status to the role of early years practitioners. This point is crucial to the purpose of this paper to engender greater engagement and discussion 
through \#ChildRightsChat on the distance between theory and practice in order to build informed, rights-based early childhood practice.

\section{Twitter and Twitter chats: 'Join the conversation'}

Launched in 2006, Twitter (https://twitter.com/) is a social media platform engaging users through micro-blogging, which at the time of its launch, was limited to posts of 140 characters in order to engender the conversational style that characterises Twitter. With a self-reported base of 126 million daily users, at March 2019, users of Twitter lists feel safe and engaged in conversations relevant to their interests. For McArthur and White (2016), the aims associated with this platform are in line with the description by Oldenburg (1999) of a conceptual 'third place', a space in which to connect to others who have similar interests and who use the space on a voluntary basis. It is perhaps this curatorial nature, through which users can define what they view and with whom they share their tweets that places Twitter in a privileged position within social media platforms in academia (Marwick \& boyd, 2010); and an appropriate site for enabling practices of knowledge exchange (Cleveland et al., 2016).

The wide reach of the platform, pushing beyond formal educational sources and enabling the contribution of practitioners and other stakeholders. This is acknowledged as a contributing factor to the effectiveness of Twitter as an opportunity for expanding learning contexts (Gao et al., 2012). Empirical studies have identified the expansion of social capital and networking as factors enabling the process of knowledge and content production (Chuang \& Chiu, 2018). These specific features have been identified as beneficial in the use of Twitter, as a strategic opportunity to broadcast an idea, a campaign, or an action to a networked audience (Marwick \& boyd, 2010).

Twitter chats build on these elements by adding the safety and comfort derived from happening at a scheduled time and being connected through agreed and shared hashtags (McArthur \& White, 2016). The concise nature of a tweet, currently contained within 280 characters, has also been identified as a fruitful opportunity to elaborate more complex analytical thinking (Cleveland et al., 2016) through curated and self-directed participation. Simply by participating in the chat, all members directly or indirectly disclose a shared interest in a cause or topic. However, social media networks 
also offer participants the possibility to choose a personal status (active or observing) and a level of intensity of participation. Consequently, participants have the possibility of selecting their positioning/role within the group (e.g., expertise, title, professional role).

\section{\#ChildRightsChat}

The accessibility and dissemination of scholarly activities and knowledge, in educational fields relating to children's lived experiences and, specifically, focused on children's rights is arguably circumscribed to specialist groups and, at times, burdened by jargon and legal specifics. Inspired by pedagogical research supporting the opportunities for democratic engagement offered by social media (Rinaldo et al., 2011), \#ChildRightsChat was designed to have a wide array of profiles and disciplines as participants. By inviting academics, practitioners, policymakers and others working in different disciplines to contribute, participants of the chat have the opportunity to explore intersecting themes across disciplines and analyse how the variety of disciplinary approaches and canons impact both research and practice of children's rights. The discussions in this chat, as a first aim, sought to emphasise the importance of knowing about children's rights (Article 42, UNCRC, 1989), not only as a right itself but also as a mechanism for social justice.

The chat consists of one-hour long, live sessions in which four or five questions as prompts are addressed by the guests, other participants and moderators. The topics that have been discussed so far include: inclusive education and inclusion, migration and forced displacement, vulnerable groups, children's participation and well-being. The first chats proposed topics that the moderators considered as of relevance to a wide range of audience. These first general discussions led to the development of a series of chat on the lived experiences of children and young people in relation to children's rights. Each chat would be advertised in advance and promoted through the use of hashtags and by tagging prior participants, engaged followers and colleagues actively discussing the field of children's rights on Twitter. The questions posed by the moderators in each chat are broad and not confined to any specific discipline, so that it was possible to include in the conversation a greater number of voices and experiences. This paper explores the opportunities and challenges of engaging different stakeholders 
and it aimed to be a learning environment suitable not only for academic researchers but also for practitioners, including teachers, social workers, lawyers, and parents.

\section{Methodology}

The research presents a form of digital ethnography (Postill \& Pink, 2012), as a means to understand the value of a social media platform to advance knowledge and practice on children's rights, using \#ChildRightsChat. The data and analyses focuses primarily on moderator observations and reflections, collected by the authors in preparation for an introduction to the chat delivered at the 2018 International Conference on Human Rights Education, as well as the anonymised engagement data derived from Twitter's analytic tool. Due to ethical constraints, anonymous engagement data was the only type of 'direct' data available about the participants that could be used in this research. Therefore, this paper offers a reflexive account by the authors, who were the creators/moderators of \#ChildRightsChat, of their experiences, to understand aspects of this 'third space' and its value to the purposes of this research.

Through adopting a critical realist approach (Alderson, 2013) in the analyses, we consider the chat in relation to different levels of reality: empirical, actual, and real (Bashkar, 2017), as a means for understanding different elements in the digital reality of \#ChildRightsChat. Critical realism is a paradigm that overcomes the epistemic fallacies of both positivist and interpretivist approaches to research, by taking into account both physical and experiential realities (Alderson, 2016). In this project, such an approach enabled the juxtaposition of raw data by tracking engagement (actual) with behaviours and types of participation exhibited during the chats (empirical). Within a forum focussed on children's rights in early childhood, adopting this unique theoretical lens, we aimed to uncover the underpinning structures (real) that enabled the opportunity for the chat to reach a form of Aristotelian 'golden middle way', between representatives of research and practice, between vocal contributors and observers, and between expertise and experience. 


\section{Analyses and Discussion}

The data are explored through a critical realist lens: empirical (reflexive experiences); actual elements (engagement data) and real (underpinning systems identified) (Bashkar, 2017). Primary data for analyses were derived from extracts from the log notes of Twitter sessions from the three authors / researchers who were also the moderators of the Twitter sessions. These short extracts are included throughout the following analyses.

McArthur and White (2016) argued the possibility that Twitter chats function as third space, using a theoretical conceptualisation presented by Oldenburg (1999) and these ideas are used to also inform the analyses of the extracts and discussion. The characteristics adapted from Oldenburg as characterising third space include: neutral ground; a levelling place; conversation as the main activity; accessibility and accommodation - inclusiveness; regular participation; choice in intensity of participation; playfulness; home away from home. These characteristics guided the identification of relevant extracts from the moderators' reflections and were organised as three themes that reflected communications and participation on the Twitter chats. These themes were: nature of the interactions that occurred among participants, features of the context that influenced participation; and the voices heard. These themes are discussed in the next sections with discussion on the implications for development of Twitter chats to support productive dialogues.

\section{Nature of the Interactions}

Since its foundation in 2018 \#ChildRightsChat has hosted 18 chats from three different series: 'Lived experiences of rights for children', 'Evidence and Reports on children's rights', and 'Knowledge and practice exchange'. Even though the numbers of engagement and participation varied in each chat, \#ChildRightsChat has made more than 50,000 impressions, which represent the number of times users see the content of the chat. It also has a global reach to all continents. Followers of the chat increased steadily every month since the project started in 2018 and, on average, had two new followers per day to March 2019. 
Interactions in \#ChildRightsChat covered three components qualifying the chat as 'third space' (McArthur \& White, 2016): conversation (identified as an opportunity to unwind and reflect on work matters), regularity in participation, and the possibility to select the intensity of interaction (whether to participate actively or simply observe). A fourth factor, playfulness, reflected a possibility to add videos, audios, GIF, or pictures; and, therefore, the possibility to disrupt formal and more traditional patterns of text interactions. The synchronous live conversations and asynchronous prompts aided in the facilitation of cross-border and interdisciplinary knowledge exchange among the participants of the network and the wider public, as identified in the following reflection.

During the chats we have experienced great moments of shared reflection and knowledge transfer, but also identified tensions and challenges in bridging the realities of parents, practitioners and scholars. (Extract 1)

The speed of the conversation and/or the personal convictions of participants can hinder an engaged understanding of multiple perspectives and the complexities of a particular topic. The chat can therefore become a platform to broadcast a fixed view or agenda. This can be particularly detrimental if participants are promoting an agenda underpinned by ideologies that fail to recognise the child as agentic actor (Salamon, 2011). This can also be counterproductive for the purpose of providing an open platform to engage in meaningful dialogue with others about issues and topics relating to children's rights. While the promotion of a positive rights message (e.g., advocating for something, or advocating against an inhibiting practice) can contribute to greater understanding about some rights issues, this approach may do little to engage and contribute to meaningful exchanges that cross disciplines and other boundaries.

This may be where the role of moderator and presence of identified responders can be useful in promoting and supporting productive and open dialogues about the topic (Cleveland et al., 2016).

Both tone and content of the tweets vary significantly between participants. The fact that chat participants come from different backgrounds and have different roles in relation to children's rights (i.e: practitioner, parent, activist, etc) leads to 
interesting scenarios. Participants have the freedom to position themselves within the role of their choice, and switch between roles in the same conversation. This results in threads in which both tone and content can vary significantly between responses. In addressing the same provocation, participants would offer both 'in my family' and 'in this research' kind of responses. The alternation between personal experiences with scholarly informed considerations can be both a possibility and a threat to the effective implementation of children's rights. (Extract 2)

Beyond the statistics of the project, the interactions within the chat are also significant as learning and teaching opportunities, making the chat and its exchange and critical dialogues relevant as an educational space.

We envisaged the chat as an opportunity to connect our students with a global network of academic and non-academic experts, policy makers, parents, teachers, other university students, and young people. We wanted to form collaborative learning communities that enabled sharing, discussion and questioning of lived experiences of rights and international perspectives on parallel rights topics or issues. This brings the 'real world' experience back into pedagogical learnings about rights and rights education. (Extract 3)

It was sometimes felt that the interactions happened primarily within the pre-existing professional boundaries. When parents/carers participated, the conversations appeared to be limited to raising an issue or sharing an experience. This distinction was less evident when a participant was positioned between two roles, for example, as a parent and an activist. Interactions had more variation and more in-depth articulation. As noted by Vaghri and colleagues (2011), in relation to GC7, the gap between real life experiences, theorisations, and policies is a complex one to bridge. The juxtaposition of personal and professional experiences with scholarly considerations had potential to shift the discourse from safeguarding/needs to discussion about actions to support rights (MacNaughton et al., 2007). 


\section{Features of the Context}

The idea of context in our case is fairly complex and multifaceted. It incorporates, in 'third space' what McArthur \& White (2016) characterised as neutrality and inclusiveness of location. This chat was established with an international outlook with the aim to encourage and facilitate international exchanges. The first complexity is in relation to the different policies and the status of children's rights in the countries represented in the chat, both in terms of moderators and contributors. However, benefits were evident as illustrated in the following extract from one moderator.

Greater insights into the diverse experiences of the same rights issues enables a richer and deeper learning experience and also strength in determining ways these challenges can be overcome. For example, while the barriers to the rights of a child with disability may share many similarities globally, the local nuances have provided opportunities for the \#ChildRightsChat community to share resources and success stories to support others in different global contexts in overcoming the challenges others experience locally.... (Extract 4)

Geographical location of the moderators impacts not only on policies that are addressed in the chat, but also on what are considered the most pressing issues and how these issues are experienced in different contexts. On an actual level, geographical differences impact the chat in terms of inclusion of contexts beyond the Global North and logistics, playing a role in both the interactions and presence of participants.

It is of importance to have the opportunity and capacity to contextualise responses in the chat. Within the space of one thread, in response to a recurrent provocation we pose on challenges identified in relation to the topic discussed, participants from different parts of the world respond, of course, very differently. A striking limitation is the absence of voices from the Global South. Thus far, we have recorded only two occasions of participation from respondents from the Global South. In both circumstances, it was clear that the chat is not as accessible as we wish, and this impacts on the representation of voices and contexts. (Extract 5) 
Aligned with the rejection of national and cultural hegemonies (Penn, 2002), the chat enabled conversation that could promote inclusion of diverse voices from all stakeholders included in the realisation of children's rights.

Thanks to the global nature of the chat we get the chance to discuss big topics through local lenses, exploring and comparing different experiences. This has however also raised some issues around the complexities of globalised discussions.

(Extract 6)

We hoped that the chat would create a space for critical readings of practices of dissemination and assimilation, encouraging a dialogue which values diversity and modus operandi which differ from what is considered normative in dominant discourses. In doing so, we viewed the promotion of interdisciplinary conversations as a factor that could promote opportunities for these 'deviations'. Similarly, the nature of the chat opposes the phenomenon of 'global panopticism' (Lingard et al., 2013), being aware of the limitedness of monitoring practices that fail to support the realisation of rights and inclusiveness, and meaningful participation (Vaghri et al., 2011).

Using such a global tool highlighted how local issues -such as forced displacement due to the drug cartels violence in Mexico- in a way resonated with challenges children face in other parts of the world, such as migration in Europe and family separation in the US. The chat allowed us to identify these commonalities and look at children's rights from a global perspective, but at the same time understand them better through their context. (Extract 7)

It is important to consider the international nature of the chat and the role this plays both in the interactions and in the presence of participants. The conversations so far have focused significantly only on the Global North, where most participants and followers of the chat are based, thus the discussions of policies and practices affecting children's rights have overlooked issues in other regions. On an empirical level, although the globalised approach of the chat aims to differ from contemporary trends of promotion and dissemination of hegemony of Western practice and theories (Burman, 
1996; Penn, 2002); more work is needed to address issues in the Global South while discussing policies affecting children from non-Western and non-hegemonic traditions.

\section{Voices Heard}

The last feature of a 'third space' is the offer of an environment that does not replicate the dynamics and conversations of regular spaces, identified by Oldenburg (1999) and McArthur and White (2016), as home and work. In this case, we argue that the possibility to interact outside professional boundaries, routines and requirements, allows for participants to explore critical discussions in a much freer manner. The chat has thus far brought together academics and practitioners working in the field, fostering partnerships, collaborations and alliances for the promotion and protection of these rights. At an actual level, it could be said that the chat aided in voicing the experiences of certain groups of stakeholders involved in advancing children's rights, although this may not always occur or be enough, as indicated in the following extract.

Lundy's provocation 'Voice is not enough'[Lundy 2007] is of great relevance in reflecting on matters of 'voice' in the chat. It is interesting to witness how the phenomenon 'voice' actualises itself in the chat. In some circumstances, participants do not engage in verbal interaction, but rather observe the exchanges silently. Does this still constitute voice and participation? What are the conditions that might enable for all to interact in active form? Is consumption of conversations to be considered nevertheless exchange of knowledge? (Extract 8)

While across the 18 chats we have had hosted academics, legal practitioners, educators and teacher educators, members of international organizations such as the UN Refugee Agency in the United Kingdom and activists from small NGOs.

When we started the chat we would never have thought we would be able to bring together so many different people into the discussion. So far we have had legal practitioners, activists, parents, researchers and members of International Organizations. Each one has contributed enormously to challenge our own understandings of issues related to children's rights. (Extract 9) 
As moderators of the chat, at an empirical level, we have frequently experienced a sense of dominance from certain voices. It would be important to further investigate whether this phenomenon is related to their background/profession, as possible result to the challenges in recognising and defining professionalism in Early Childhood (Moloney, 2010; Ortlipp et al., 2011). Some responders, particularly activists and academics, seems to have a stronger presence/voice and engage in challenging others' perspectives within the responses in a thread.

On an empirical level we noticed that, when participants feel comfortable and within what they identify as their area of experience/expertise, the voice in the conversation seems to lead to a more active exchange of knowledge. Whilst the chat promotes a participatory and judgement free culture (Hitchcock \& Young, 2016), it is important to explore 'the real' to identify which underlying systems impact participants' voices. The insecurity and the feeling of lack of expertise relative to others who may also be participating, viewing, or accessing the interactions may therefore impact the possibility to lead openly critical conversations.

\section{It is incredibly important that the chat enables participation of very different voices, that otherwise might not have shared platforms. I wish we could effectively engage children and young people too. (Extract 10)}

Despite the focus on the lived experiences of rights for children, making sure that voices of children are represented remains a challenge. Facilitating the participation of children is a complex matter given the nature of the social media platform and the associated policies and practices (Hitchcock and Young, 2016; Livingstone and Brake, 2010). This issue replicates, or perhaps even enhances, challenges experienced in 'regular' spaces with regards to child's participation.

\section{Conclusions}

Through critically reflecting on the use of the chat as a learning environment for knowledge exchange and networking to promote and protect the rights of children, we recognise how the interactions in it represented opportunities, especially for early years practitioners. These spaces can act as communities of practice in which practitioners not 
only can share their own experiences but can also learn from the experiences of others in different contexts and disciplines. The knowledge exchange that occurs as a result of the dialogue and discussions in the chat gives early years practitioners a third space (McArthur \& White, 2016) to reflect on professional practices from a rights-based perspective and, by engaging collectively in a process of mutual development.

While initially we felt there was a balance between representatives of research and practice, between vocal contributors and observers, and lastly between expertise and experience, through the critical realist reflection of \#ChildRightsChat as a third space we realised this 'golden middle way' has not been achieved. Although it is a productive and dynamic space for dialogues and discussions about children's rights in early childhood the interactions so far have, unintentionally, overlooked important contexts and voices. Despite this important limitation, we do recognise the chat as a valuable educational space that allows the start of interdisciplinary and global dialogues more inclusive dialogues could be built about policies and practices focused on the rights of children.

The critically reflexive stance we have now applied to analysing this space, will influence its future directions because there will be greater cognisance of content, style, and interactions that might help to achieve the desired balance for inclusiveness. The analyses raise necessary questions on the variety of disciplinary approaches and canons that may impact education, research, and practice about children's rights. In addition, the analysis further highlights the importance of advancing an intersectional lens, reflected in \#ChildRightsChat in the guests and topics covered. There is a need to foster more discussion on topics specifically related to the intersection between children's rights and different forms of oppression such as racism, sexism, ableism, and so on. From these discussions as well as guests' experiences, the chat as a digital space demonstrates the importance of knowing about children's rights (Article $42^{\circ} \mathrm{UNCRC}$ ), as a mechanism for social justice.

Reflecting on the status of children's rights in early years, we also suggest that the project has the potential to be used as a tool for professional development of EY practitioners based on the knowledge exchange and reflection on practices that occurs in 
the conversations and interactions among moderators, invited guests and participants. These conversations, as the reflections on the interactions indicate, reinforce the importance of dialogue as a central element for Human Rights Education (Lohrenscheit, 2006; Zembylas et.al., 2016) by incorporating the lived experiences of practitioners as content from which to learn from but also as pedagogical tools to foster further analysis and discussion (Osler \& Zhu, 2011).

Children's rights are variably considered within Early Childhood as children's agentic capabilities are often considered commensurate to their age (Mayall, 2006; Moss, 2004). A similar 'top-down' approach has been observed also in the translation of policies and theories in the practice context. Marpinjun and colleagues (2018) identify a great opportunity in ECEC for subverting normative and Western-centric models by engaging with feminist practices aimed at developing resistance from patriarchal and neoliberal models and promoting social justice.

In this sense, we welcome the opportunity to further develop a project such as \#ChildRightsChat as third space for early years practitioners and scholars to engage in critical discussions of children's rights.

\section{References}

Arrabal, A. A. (2015). Comparing early childhood education and care from a rights-based approach. Revista Española de Educación Comparada, 25, 47-63.

Alderson, P. (2013). Childhoods real and imagined: An introduction to critical realism and childhood studies. London, UK: Routledge.

Alderson, P. (2016). The philosophy of critical realism and childhood studies, Global Studies of Childhood, 6(2), 199-210.

Bashkar, R. (2017). The order of natural necessity. In G. Hawke (Ed.), A kind of introduction to critical realism. London, UK: Amazon.

Burman, E. (1996). Local, global or globalized? Child development and international child rights legislation. Childhood, 3(1), 45-66.

Campbell-Barr, V. \& Nygård, M. (2014). Losing sight of the child? Human capital theory and its role for early childhood education and care policies in Finland and England since the mid-1990s. Contemporary Issues in Early Childhood. 15(4), 346-359.

Chuang, L.W. \& Chiu, S. (2018). Evaluating key factors affecting knowledge exchange in social media community. MATEC Web Conf., 169 (ee 01023), 1-5.

Cleveland, S., Jackson, B. C., \& Dawson, M. (2016). Microblogging in higher education: Digital Natives, knowledge creation, social engineering, and 
intelligence analysis of educational tweets. E-Learning and Digital Media, 13(1-2), 62-80.

Cook, D. T. (2015). A politics of becoming: When 'child' is not enough. Childhood. 22(1), $3-5$.

Davies, B. (2014). Listening to children. Being and becoming. London, UK: Routledge.

Gao, F., Luo, T., \& Zhang, K. (2012). Tweeting for learning: A critical analysis of research on microblogging in education published in 2008-2011. British Journal of Educational Technology, 43, 783-801.

Ghirotto, L. \& Mazzoni, V. (2013). Being part, being involved: the adult's role and child participation in an early childhood learning context, International Journal of Early Years Education, 21(4), 300-308.

Gillett-Swan, J. K. \& Sargeant, J. (2018). Unintentional power plays: interpersonal contextual impacts in child-centred participatory research, Educational Research, 60(1), 1-16.

Haustein, S., Sugimoto, C.R. \& Lariviere, V. (2015). Social media in scholarly communication. Journal of Information Management, 67(3), 1-15.

Herczog, M. (2012). Rights of the Child and Early Childhood Education and Care in Europe. European Journal of Education, 47(4), 542-555.

Hitchcock, L. I. \& Young, J. A. (2016). Tweet, tweet: using live Twitter chats in social work education. Social Work Education, 35(4), 457-468.

Jensen, A. \& Qvortrup, J. (2004). Summary: A childhood mosaic: 'What did we learn?' In A.M. Jensen, A. Ben-Arieh, C. Conti, D. Kutsar, M.N.G. Phidraig, \& H. W. Nielsen (Eds.). Children's welfare in ageing Europe. Trondheim, Norway: Norwegian Centre for Child Research.

Kivunja, C. (2015). The efficacy of social media technologies in academia: a pedagogical bliss or digital fad? International Journal of Higher Education, 4(4), 33-44.

Kortelainen, T. \& Katvala, M. (2012). 'Everything is plentiful - Except attention'. Attention data of scientific journals on social web tools, Journal of Informetrics, 6(4), 661-668.

Livingstone, S. \& Brake, D. R. (2010). On the rapid rise of social networking sites: new findings and policy implications. Children \& Society, 24, 75-83.

Lingard, B., Martino, W., \& Rezai-Rashti, G. (2013). Testing regimes, accountabilities and education policy: Commensurate global and national developments. Journal of Education Policy, 28(5), 539-556.

Lohrenscheit, C. (2006). Dialogue and Dignity - Linking Human Rights Education with Paulo Freire's 'Education for Liberation'. Journal of Social Science Education, 5(1), 126-134. http://www.jsse.org/index.php/jsse/article/viewFile/1006/909

Lundy, L. (2007). Voice is not enough: Conceptualising Article 12 of the United Nations Convention on the Rights of the Child. British Educational Research Journal, 33, 927-942. 
Marpinjun, S., Rengganis, N., Andri Riyanto, Y. \& Yuni Dhamayanti, F. (2018). Feminists' strategic role in early childhood education. In R. Rosen \& K. Twamley (Eds.). Feminism and the Politics of Childhood or Foes? London, UK: University College Press.

Marwick, A. E., \& boyd, d. (2010). I tweet honestly, I tweet passionately: Twitter users, context collapse, and the imagined audience. New Media \& Society, 20, 1-20.

Mayall, B. (2006). Values and assumptions underpinning policy for children and young people in England. Children's Geographies, 4(1), 9-17.

McArthur, J. A., \& White, A. F. (2016). Twitter Chats as Third Places: Conceptualizing a Digital Gathering Site. Social Media \& Society, 2(3), 1-9.

Moody, Z. \& Darbellay, F. (2019). Studying childhood, children, and their rights: The challenge of interdisciplinarity. Childhood, 26(1), 8-21.

Moloney, M. (2010). Professional identity in early childhood care and education: perspectives of pre-school and infant teachers. Irish Educational Studies, 29(2), $167-187$.

Moss, P. (2004). The early childhood workforce structure in "developed" countries: basic structures and education. UNESCO Policy Brief on Early Childhood, 27. Paris, France: UNESCO.

MacNaughton, G. M., Hughes, P., \& Smith, K. (2007). Early childhood professionals and children's rights: tensions and possibilities around the United Nations General Comment No. 7 on Children's Rights. International Journal of Early Years Education, 15(2), 161-170.

Oldenburg, R. (1999). The great good place: cafes, coffee shops, bookstores, bars, hair salons, and other hangouts at the heart of a community. New York, NY: Marlowe \& Company.

Ortlipp, M., Arthur, L. \& Woodrow, C. (2011). Discourses of the early years learning framework: Constructing the early childhood professional. Contemporary Issues in Early Childhood, 12(1), 56-70.

Osgood, J. (2006). Deconstructing professionalism in early childhood education: resisting the regulatory gaze. Contemporary Issues in Early Childhood, 7(1), $5-14$.

Osler, A., \& Zhu, J. (2011). Narratives in teaching and research for justice and human rights. Education, Citizenship and Social Justice, 6(3), 223-235.

Penn, H. (2002). The World Bank's View of Early Childhood. Childhood, 9(1), $118-132$.

Postill, J. \& Pink, S. (2012). Social media ethnography: the digital researcher in a messy web. Media International Australia, 145(1), 123-134.

Rinaldo, S. B., Tapp, S. \& Laverie, D. A. (2011). Learning by tweeting: Using Twitter as a pedagogical tool, Journal of Marketing Education, 33(2), 193-203.

Robson, J. (2016). Early Years Teachers and young children's rights: the need for critical dialogue. Research in Teacher Education, 6(1), 6-11. 
Rutanen, N. \& Colus, K. M. (2014). What is the best for the child? Early Childhood Education and Care for Children under 3 years of Age in Brazil and in Finland. International Journal of Early Childhood, 46, 123-141.

Salamon, A. (2011). How the Early Years Learning Framework can help shift pervasive beliefs of the social and emotional capabilities of infants and toddlers. Contemporary Issues in Early Childhood, 12(1), 4-10.

United Nations (1989). Convention on the Rights of the Child (UNCRC). Geneva, Switzerland.

Vaghri, Z., Arkadas, A., Kruse, S., \& Hertzman, C. (2011). CRC General Comment 7 Indicators Framework: A tool for monitoring the implementation of child rights in early childhood. Journal of Human Rights, 10(2), 178-188.

Woodhead, M. (2006). Changing perspectives on early childhood: theory, research and policy. International Journal of Equity and Innovation in Early Childhood, 4(2), $1-43$.

Zembylas, M., Charalambous, P., Charalambous, C., \& Lesta, S. (2016). Toward a critical hermeneutical approach of human rights education: universal ideals, contextual realities and teachers' difficulties. Journal of Curriculum Studies, $1-21$. 